\title{
BLENDED LEARNING: IMPLICATIONS FOR GROWTH AND ACCESS
}

\author{
Anthony G. Picciano \\ School of Education, Hunter College \\ Doctoral Programs in Urban Education, and Interactive Pedagogy and Technology, \\ City University of New York Graduate Center
}

\begin{abstract}
The purpose of this paper is to reflect on issues of growth and access in blended learning environments. Increasingly decision makers throughout higher education are considering blended learning as an important component of their academic programs. It is hoped that this paper will help to provide insight for these decision makers. Many of the thoughts and ideas in this paper evolved out of discussions on Growth Paradigms held at the 2005 Sloan-C Summer Workshop in Victoria, British Columbia, and the 2004 and 2005 Sloan-C Workshops on Blended Learning held in Chicago.
\end{abstract}

\section{KEYWORDS}

Distance Learning, Online Learning, Blended Learning, Hybrid Learning, Access, Pedagogy, Decision Making, Administration, Attrition, Retention

\section{INTRODUCTION}

\section{A. Vignette 1}

A public urban university (USF) in the Sunbelt has been experiencing unprecedented enrollment growth as a result of a population boom that has continued for more than fifteen years. Enrollments in its programs are increasing at the rate of $7-9 \%$ per year. State funding has been stagnant and has been increasing at less than or at the rate of inflation. While there has been modest funding for building construction, there is a dire shortage of classroom and other teaching facilities. The university has an excellent technology infrastructure and has been offering online courses since 1997. During the past few years, there has been a significant increase in faculty teaching blended courses where part of a course's class time is replaced by an online component. The USF president's cabinet has been discussing the classroom shortage and one suggestion is to expand and formalize the blended learning activities in such a way as to recapture classroom space. Presently faculty determine on a course by course basis what they will do online, however, there is no system in place to recapture the classroom space freed up as a result of the online component of the course. The Provost and Chief Information Officer have proposed that all required courses normally taken in the freshmen or sophomore year include at least a one-third (33\%) online component. Classroom space will be assigned to recapture the one-third portion of the classes taught online. This will provide a significant increase of classroom space with little additional expense. The president's cabinet approves the proposal and USF is presently working with faculty to convert all freshmen and sophomore required courses to a blended format. 


\section{B. Vignette 2}

A program coordinator (C.S.) for an online MBA at a college that specializes in adult, continuing, and distance learning, brought her full-time faculty together to consider offering a variation of the program to require students to meet face-to-face. She offered this proposal because while the fully online MBA program was well enrolled and considered successful, student evaluations of the program indicated that they would like opportunities to meet with their fellow students. The faculty were wellexperienced in online learning but tended to agree with C.S.'s suggestion. A small committee was formed to work out the logistics and details. One year later a second version of the online MBA program was offered that required students to meet once a month on Saturdays in face-to-face mode at the College. The purpose of the face-to-face meetings was to engage in group work, to do project presentations, and to socialize/bond with one another.

These two vignettes are examples of the decisions that administrators and faculty are considering regarding the development of blended learning in American colleges and universities. The decision in the first vignette, while essentially being driven by the need to provide more access to students by freeing up classroom space, includes a significant pedagogical outcome, namely that all undergraduate required courses contain an online component. The second vignette appears to be basically a pedagogical decision on the part of the program coordinator and faculty to offer a blended version of a fully online program. However, if successful, the new blended program might attract and retain more students in the M.B.A. programs, thereby increasing access to education. The point is that decisions to develop, implement, or expand blended learning environments can involve multiple perspectives and rationales, frequently including issues of access and pedagogy. In many cases, faculty and administrative decision makers consider these perspectives together.

The purpose of this paper is to reflect on issues of growth and access in blended learning environments. Increasingly decision makers throughout higher education are considering blended learning as an important component of their academic programs. It is hoped that this paper will help to provide insight for these decision makers. Many of the thoughts and ideas in this paper evolved out of discussions on Growth Paradigms held at the 2005 Sloan-C Summer Workshop in Victoria, British Columbia, and the 2004 and 2005 Sloan-C Workshops on Blended Learning held in Chicago.

\section{DEFINING BLENDED LEARNING}

Blended learning is not one thing. It comes in many shapes, flavors, and colors. In one course, blended learning may be used to enhance the traditional lecture with electronic instructor notes, additional readings, and images of charts, graphs, or other handouts. In another course, online learning may be combined with face-to-face instruction so that rather than meeting in a classroom three hours a week, a course meets two hours per week with the third hour consisting of an online threaded discussion. As described by Gary Miller, Associate Vice President for Outreach, and former Executive Director of The World Campus, the Pennsylvania State University recently went through a lengthy process resulting in the definition of five variations of "blended learning" environments [1].

In the broadest sense, blended learning (see Figure 1) can be defined or conceptualized as a wide variety of technology/media integrated with conventional, face-to-face classroom activities. However, the blended learning variation examined in this paper focuses on an online component with some replacement of seat time in the conventional classroom (see Figure 2). This definition was discussed extensively at the 2004 and 2005 Sloan-C Workshops on Blended Learning held in Chicago. The two core elements (online and face-to-face instruction) of this definition were deemed critical to the 
definition. This definition eliminates certain forms of stand-alone media such as videotape, CD-ROM, or DVD that might be used solely in a face-to-face course. It would not eliminate these media if used in a course that had both an online and a face-to-face component.

Faculty in the Sloan-C workshops also discussed whether higher education should be considering a true blend, and focusing on the ways in which faculty might best integrate these two modes to create a new whole. Like turning on the electronic appliance called a blender, faculty may seek ways to blend smoothly and seamlessly the two components together into something new as opposed to just tacking one mode (e.g., online) onto the other mode (face-to-face).

At the 2005 Sloan-C Workshop on Blended Learning, the following was adopted by the participants and will serve as the accepted definition of blended learning for this paper:

1. Courses that integrate online with traditional face-to- face class activities in a planned, pedagogically valuable manner; and

2. Where a portion (institutionally defined) of face-to-face time is replaced by online activity [2].

While the research base on blended learning is sparse, indications are that many faculty in American colleges and universities are willing to incorporate blended learning into their pedagogical repertoire. However, the extent and the "why" of this willingness is not clear and needs further examination.

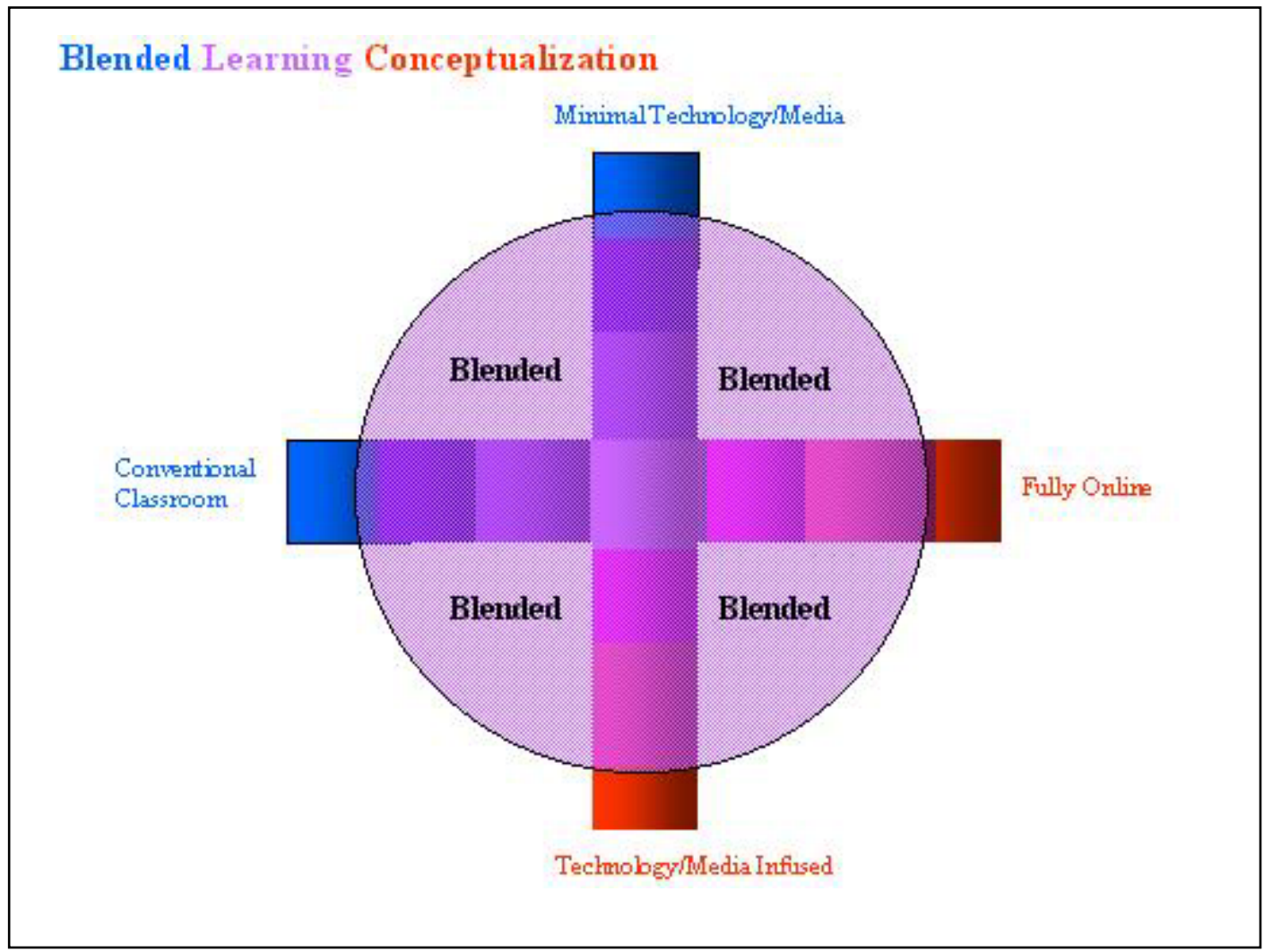

Figure 1: Broad Conceptualization of Blended Learning

Source: Picciano, A.G. (February 9, 2005). Posting to the Official Website of the 2005 Sloan-C Summer Workshop held in Victoria, British Columbia.

(Note: Conceptualization discussed at meetings of the Planning Committee for the 2005 Sloan-C Workshop on Blended Learning held in Chicago.) 


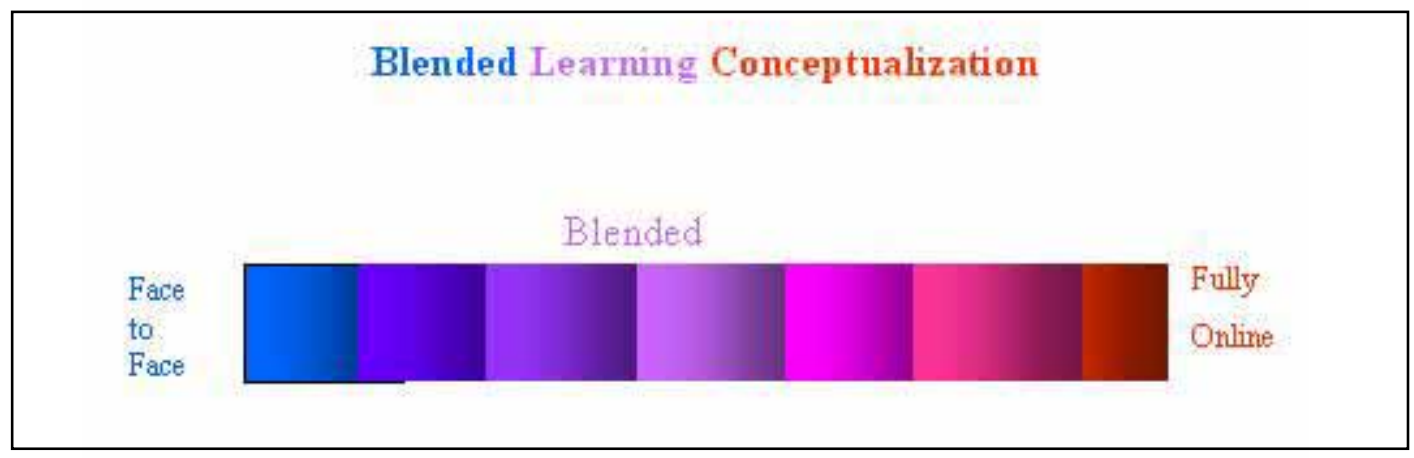

Figure 2. Online-Specific Conceptualization of Blended Learning

Source: Picciano, A.G. (January 22, 2005). Posting to the Official Website of the 2005 Sloan-C Summer Workshop held in Victoria, British Columbia.

(Note: Conceptualization discussed at meetings of the Planning Committee for the 2005 Sloan-C Workshop on Blended Learning held in Chicago.)

\section{GROWTH AND ACCESS}

\section{A. Online Learning and Access}

In 2004, a majority of all American colleges and universities were offering fully online courses enrolling approximately 2 million students. In public sector institutions especially where increasing student access to education is an important part of their missions, the percentage offering online courses was as high as $90 \%$ [3]. In a national survey of chief academic officers, Allen \& Seaman reported that $52.6 \%$ viewed online learning as critical to their institution's overall long-term strategy [3].

American higher education provides extensive opportunities for high school graduates to pursue postsecondary education. Fully $75 \%$ of high school graduates enroll in a college or university within two years of graduation [4]. One of the major rationales for many colleges and universities in developing fully online programs was to provide greater access to an education for their students. The early leaders in online learning in the 1990s such as The Pennsylvania State University World Campus and the University of Maryland University Campus had well-established distance learning programs designed to provide higher education opportunities to students who for a variety of reasons were unable to enroll in a traditional college or university. For many of these students, geography and physical distance were the major barriers. However, as online learning evolved, it became evident that physical distance was not the only impediment to students' ambitions for higher education. Colleges and universities with little history in traditional distance learning programs such as the University of Central Florida and the City University of New York provided online opportunities for local residents, many of whom combined work, family, and education activities into incredibly busy days. For these students, the "distance" was not geography but time. As online learning matured, more faculty began offering online courses and typically students enrolled regardless of their physical distance or time constraints. Many stories are told of full-time students who live on campus in dormitories enrolling in online courses. The literature and research base on fully online courses has grown considerably in the past ten years and much of it supports the position that online learning has had an important role in providing greater opportunities for students to pursue higher education.

Access to an education can be measured in several ways. For many publicly-funded (especially community colleges) and for the growing for-profit institutions, increased enrollments are evidence of 
greater educational opportunity (access) for their students. Enrollments, however, might increase for several reasons including:

1. more incoming freshmen,

2. more transfer students,

3. more readmitted students (students who had left and are now returning to the same college), or

4. greater retention of existing students.

Fully online courses surely helped to increase enrollments at individual colleges/programs especially in attracting more students (categories 1 through 3 above). As mentioned in the previous paragraphs, the rationale for online learning was to extend learning opportunities for students not able to attend college because of distance or time. For many institutions, this worked well and there is little question that online learning improved access as measured by more new students enrolling in a specific college. However, the evidence is not strong that fully online learning helped to retain students. On the contrary, a number of studies indicate that drop-out rates are higher in online courses than in face-toface courses [5, 6, 7, 8]. During the past three decades, student retention in higher education has evolved as a major issue. Data on this issue are sketchy mainly because students move and transfer from one institution to another on a fairly regular basis so that one school's drop-out is another's new enrollment. The Lumina Foundation, which supports and maintains a website on student retention, reports that only 55\% of bachelor degree seeking students will graduate within six years in the same institution and only 63\% will receive a degree from any institution [9]. An important question for the purposes of this paper is whether or not blended learning environments might help to improve retention rates among post-secondary students and thereby increase access.

\section{B. Blended Learning: Access and Pedagogy}

With the advent of blending learning, the relationship of student access to pedagogical practice becomes more complex. During the past few years what has become a most interesting but little understood phenomenon is the evolution of blended learning wherein faculty offer parts of their courses online and parts in face-to-face mode. While there are individual accounts and case studies, there has been little formal cross-institutional research of blended learning mainly because many college administrations have not implemented adequate data collection processes for identifying blended courses. In many of these situations, faculty are making decisions about blended learning purely for pedagogical reasons and are trying to capture the best of online and traditional face-to-face modalities. For these faculty, access to higher education was not an integral part of their decision process. They simply tried to blend activities to best meet the learning needs of their students. However, as administrators (program heads, department chairpersons, deans, etc.) have become aware of the growth of the blended learning phenomenon in their schools, they have begun to seek ways to recapture precious resources especially space and facilities to provide more opportunities for their students.

The literature on the pedagogical benefits of fully online learning has evolved for the past ten years. Most of these studies indicate that online learning is perceived to be at least as effective as face-to-face classes [10, 11, 12, 13, 14, 15]. More recently, some of the literature is suggesting that for certain subject matters with certain students, online learning may be more appropriate than face-to-face classes. Pedagogical techniques such as reflective teaching practice, collaborative learning, selfpacing, and intensive writing may work better in online learning environments [16]. With blended learning environments, faculty design programs and courses to mix and match the two teaching modalities. While the research on this is just beginning to be done, a safe assumption is that many faculty are using the blended design to take advantage of the best pedagogical techniques of online and 
face-to-face learning [17]. If this assumption is correct, then speculation on the benefits of blended learning on retention can be considered.

The literature on student attrition and retention is extensive. Among many others, the work of Vincent Tinto, a leading authority on student attrition and retention, is recommended for gaining insights into these issues. Suffice it to say that for many students, the decision to stay in a college program, to leave to go to another college or to leave higher education altogether is a multivariate decision. However, the two critical elements of this decision are academic factors such as difficulty with course material and non-academic factors such as family responsibilities, work responsibilities, or financial need. Online learning is already perceived to meet a number of student non-academic needs related to time pressure because of family and work responsibilities. If specific forms of online learning are evolving that better meet certain student academic needs, then that model might help improve retention of students as well. Tinto specifically recommends that to improve retention, colleges and universities must be committed to developing comprehensive strategies that seek to involve students in learning specifically stated as:

"The more students learn, the more value they find in their learning, the more likely they are to stay and graduate” [18].

The blended learning model may be more effective in this regard in retaining students than either the fully online or fully face-to-face model. This is speculative but the assumptions on which it is based, are real. Blended learning provides additional tools for faculty to design multimodal activities that better address the diverse learning styles of students be they visual learners, adult learners, or ESL students. The emphasis is on designing sound pedagogical approaches and using a variety of tools to meet diverse student needs. The intention here is not to present blended learning as the "silver bullet" that will automatically improve retention but to suggest that it might be better than either fully online or fully face-to-face environments. Surely more research on student retention in blended versus other single learning modalities is needed. However, a hypothesis can be posited that well-designed blended learning environments have the potential of increasing access to a higher education because they improve retention. This hypothesis is in need of study and research and it is hoped that this paper might generate activity in this area.

\section{CONCLUDING COMMENTS}

The issues of access and growth presented in this paper were discussed extensively during the 2005 Sloan-C Summer Workshop, and the 2004 and 2005 Sloan-C Workshops on Blended Learning held in Chicago. The participants in these workshops constituted a group of administrators and faculty experienced in looking at issues of online learning. Through the efforts of researchers including those at Sloan-C, the literature on online learning has been developing well and provides insights into the influences of this learning modality on higher education. However, while the research base on blended learning is not yet developed, its influence on higher education may be far greater in the years to come. This paper attempts to establish a research interest in the influence of blended learning on student access and suggests that access and growth will improve in blended learning environments when carefully designed for pedagogically appropriate reasons. .

\section{ACKNOWLEDGEMENTS}

The author of this paper is grateful to colleagues who participated in the 2005 Sloan-C Summer Workshop, the 2004 Sloan-C Workshop on Blended Learning, and 2005 Sloan-C Workshop on 
Blended Learning: Implications for Growth and Access

Blended Learning. They provided most of the insights presented in this paper. The author also thanks Elaine Bowden for reviewing earlier drafts of this article and offering her suggestions.

\section{REFERENCES}

1. Miller, G. Blended learning and Sloan-C. Posting to the Official Website of the 2005 Sloan-C Summer Workshop held in Victoria, British Columbia, June 30, 2005.

2. Laster, S., G. Otte, A. G. Picciano and S. Sorg. Redefining blended learning. Presentation at the 2005 Sloan-C Workshop on Blended Learning, Chicago, IL, April 18, 2005.

3. Allen, I. E. and J. Seaman. Entering the Mainstream: The Quality and Extent of Online Education in the United States, 2003 and 2004. Needham, MA: Sloan-C, 2004. http://www.sloan-c.org/resources/survey04a.asp.

4. Schneider, C. G. Liberal education. Slip sliding away? In R. H. Hersh and J. Merrow (eds.), Declining by Degrees. New York: Palgrave Macmillan, 2005.

5. Dutton, J., M. Dutton and J. Perry. Do online students perform as well as lecture students? Journal of Engineering Education 90(1): 131-139, 1999.

6. Terry, N. Assessing enrollment and attrition rates for the online MBA. T.H.E. Journal 28(7): 64-68, 2001.

7. Willging, P. A. and S. Johnson. Factors that influence students' decision to dropout of online courses. Journal of Asynchronous Learning Networks 8(4): 2004. http://www.sloan-c.org /publications/jaln/v8n4/v8n4_willging.asp.

8. Thaiupathump, C. J. Bourne and O. Campbell. Intelligent agents for online learning. Journal of Asynchronous Learning Networks 3(2): 1999. http://www.sloan-c.org/publications/jaln /v3n2/v3n2_choon.asp.

9. Lumina Foundation. Lumina Foundation focus: How extensive is the dropout problem.

10. Jiang, M. and E. Ting. A study of factors influencing students' perceived learning in a webbased course environment. International Journal of Educational Telecommunications 6(4): 317338, 2000.

11. Picciano, A. G. Beyond student perceptions: Issues of interaction, presence, and performance in an online course. Journal of Asynchronous Learning Networks 6(1): 2002. http://www.sloan-c .org/publications/jaln/v6n1/v6n1_picciano.asp.

12. Picciano, A. G. Developing an asynchronous course model at a large, urban university. Journal of Asynchronous Learning Networks 2(1): 1998. http://www.sloan-c.org/publications /jaln/v2n1/v2n1_picciano.asp.

13. Shea, P., E. Fredericksen, A. Pickett, W. Pelz and K. Swan. Measures of learning effectiveness in the SUNY Learning Network. In J. Bourne and J. C. Moore (eds.), Online Education 2: Proceedings of the 2000 Sloan Summer Workshop on Asynchronous Learning Networks. Needham, MA: Sloan-C, 2000.

14. Hartman, J. L. and B. Truman-Davis. Factors related to the satisfaction of faculty teaching online courses at the University of Central Florida. In J. Bourne and J. C. Moore (eds.), Online Education 2: Proceedings of the 2000 Sloan Summer Workshop on Asynchronous Learning Networks. Needham, MA: Sloan-C, 2000.

15. Dziuban, C. and P. Moskel. Emerging research issues in distributed learning. Orlando, FL: Paper delivered at the 7th Sloan-C International Conference on Asynchronous Learning Networks, 2001.

16. Picciano, A. G. Online learning: Implications for higher education pedagogy and policy. Journal of Thought, in press.

17. Godambe, D., A. G. Picciano, R. Schroeder and C. Schweber. Faculty perspectives. Presentation at the 2004 Sloan-C Workshop on Blended Learning, Chicago, IL, April 27, 2004. 
18. Tinto, V. Establishing conditions for student success. Keynote Presentation at the Annual Conference of the European Access Network, Monash Univeristy, Prato, Italy, June 22, 2002. http://www.ean-edu.org/news/tinto-pratoconf.pdf, accessed August 15, 2005.

\section{ABOUT THE AUTHOR}

Anthony G. Picciano is a professor in the Educational Leadership program at Hunter College. He is also a professor in the Ph.D. Program in Urban Education and the program in Interactive Pedagogy and Technology at the City University of New York Graduate Center. His teaching specializations include educational technology, contemporary issues in education, educational policy, organization theory, and research methods. He is the author of seven books including Educational Leadership and Planning for Technology, 4th Ed. (Pearson, 2005), Data-Driven Decision Making for Effective School Leadership (Pearson, in press), Educational Research Primer (Continuum, 2004), and Distance Learning: Making Connections across Virtual Space and Time (Merrill/Prentice Hall, 2001). He has received a number of grants and awards from the National Science Foundation, the Alfred P. Sloan Foundation, the US Department of Education, and IBM. He currently serves on the Board of Directors of the Sloan Consortium. His articles and reviews have appeared in journals such as The Teachers College Record, The Urban Review, Journal of Asynchronous Learning Networks, Journal of Thought, Journal of Educational Multimedia and Hypermedia, Computers in the Schools, Equity and Choice, and EDUCOM Review. 